\title{
Penetration of Salmonella enteritidis in Chicken Breasts Stored Under Refrigeration Temperatures
}

Claudia Regina Wessling (I), Cibeli Viana (I), Vanessa Mendonça

Soares (II), Camila Lampugnani (I), Ana Paula Perin (I), Krishna

Raquel Marques (I), Luciano dos Santos Bersot (I)

(I) UFPR - Universidade Federal do Paraná, Setor Palotina (Rua Pioneiro, 2153, Jardim Dallas, Palotina, PR CEP 85950-000), (II) UNESP - Universidade Estadual Paulista, Campus de Botucatu (Distrito de Rubião Júnior, caixa postal 572, CEP 18618970, Botucatu, SP)

\section{Resumo}

It is widely studied the importance of Salmonella sp. in contamination of chicken meat and its relationship with the occurrence of outbreaks. The chicken can contaminate throughout the slaughter and processing occurring initially on the surface. Studies indicate that Salmonella has ability to penetrate the muscle tissue facilitated by autolytic processes or presence of proteolytics microorganisms in muscle tissue, mostly in storage at inadequate temperatures. The penetration of Salmonella at deeper layers of tissue can be difficult to eliminate by usual food preparation processes and increase the risk of transmission of this foodborne pathogen. Thus, the objective of the present research was to assess the ability of Salmonella Enteritidis in penetrating poultry breasts at refrigeration temperatures and the influence of the Pseudomonas fluorescens in this process. Chicken cubes were developed with $30 \times 30 \times 30 \mathrm{~mm}$ (height, width, length) from chicken breasts in natura. Inocula were prepared from $3 \mathrm{Log}$ CFU of S. Enteritidis and Pseudomonas fluorescens ATCC 13525, which were placed in contact with only one side of the chicken cubes. Two treatments were performed, being the treatment I (cube inoculated with S. Enteritidis) and treatment II (cube of chickens inoculated with S. Enteritidis and P. fluorescens). The treatments I and II were exposed to 2,7 and $12^{\circ} \mathrm{C}$ for 24 , 48 and 72 hours. After each time the cuts were subdivided into three 
segments of $10 \mathrm{~mm}$ height: base (near the site of inoculation), medium and final that were submitted to quantification of microorganisms inoculated by ISO methodology. The analysis were carried out in duplicate for each time and temperature, and the experiment was performed in six repetitions. It was found that there was no statistical difference $(\mathrm{P}<0.05)$ between treatments I and II, having been possible to quantify S. Enteritidis in all segments to $12^{\circ} \mathrm{C}$, which was not possible to observe the 2 and $7{ }^{\circ} \mathrm{C}$, where it was not quantified the pathogen at the top in both treatments. These results demonstrated that the penetration of $\mathrm{S}$. Enteritidis in chicken breasts had influence of temperature of storage, the highest being more likely to facilitate the penetration and the presence of $P$. fluorescens not affected on the penetration of the pathogen in the experimental conditions.

Palavras-Chave: food, contamination, cooking Agência de Fomento: Fundação Araucária 